\title{
EL HOMBRE COMO ANIMAL: EL ANTROPOCENTRISMO EN LA ZOOLOGÍA
}

\author{
José Luis Viejo Montesinos \\ Departamento de Biología. Universidad Autónoma de Madrid.
}

\section{RESUMEN}

La taxonomía y la nomenclatura zoológicas han estado siempre sometidas a un considerable antropocentrismo. Desde Linneo, la mayoría de las clasificaciones colocan al hombre en un lugar preeminente y único entre los animales, quizá como herencia de la cultura griega ("El hombre es la medida de todas las cosas"). Este prejuicio ha conducido a veces hacia una interpretación etnocéntrica de la evolución y la paleontología humana.

\section{ABSTRACT}

Zoological taxonomy and nomenclature have always been subject to great anthropocentrism. Since Linnaeus, most of classifications place Man in a preeminent and unique position among animals, may be as a Greek culture heritage ("Man is the measure of everything"). This prejudice has sometimes given rise to an ethnocentric explanation of the evolution and human paleontology.

Sócrates: [...] ¿dices que el conocimiento es una percepción?

Teeteto: Sí.

Sócrates: Seguramente has pronunciado una palabra no banal acerca del conocimiento, la que decía también Protágoras. Él afirmó exactamente esto, aunque de manera distinta. Sostiene que el hombre es la medida de todas las cosas.

Platón. Teeteto.

\section{LA TAXONOMÍA EN LAS SOCIEDADES PRIMITIVAS.}

Clasificar no es un trabajo inocente. La clasificación de un conjunto de objetos más o menos heterogéneos normalmente implica la aceptación de una cierta relación entre ellos, de modo que los subconjuntos resultantes del proceso clasificador revelan implícitamente un criterio, una opinión acerca de los posibles vínculos entre los objetos clasificados. 


\section{JOSÉ LUIS VIEJO MONTESINOS}

Entre todos los entes y objetos que han rodeado a los seres humanos desde sus orígenes, los organismos vivos probablemente han sido los que han despertado más interés, sin duda a causa, entre otras, de su dependencia respecto a su supervivencia (alimentación, vestido, defensa, materias primas, etc). Esta íntima relación con animales y plantas, junto a la innata propensión de los seres humanos por denominar, agrupar y clasificar los objetos que le rodean, ha conducido a las diferentes culturas a ordenar los seres vivos en categorías taxonómicas, en general teñidas de rasgos subjetivos (utilidad, semejanza a sí mismo, etc) y, por tanto, antropocéntricas.

Probablemente antes de que el hombre actual (Homo sapiens sapiens) surgiera en algún lugar de África, sus antepasados ya debieron conocer y utilizar numerosos organismos vivos (animales y plantas) para su propio beneficio. $\mathrm{Y}$ aunque conocer no implica necesariamente clasificar y denominar, ciertamente es la antesala de una incipiente taxonomía. Sin especular con los conocimientos botánicos y zoológicos de nuestros antepasados homínidos más remotos, podemos situarnos en el estado biológico evolutivo presente, pero en los albores de nuestra especie, y plantear la relación que aquellas primeras poblaciones de seres humanos debieron mantener con su medio.

Los seres humanos han llevado una vida de cazadores-recolectores la mayor parte de su existencia en la biosfera, desde su aparición, hace unos 100.000 años, hasta hace unos 10.000 años, cuando comienza a extenderse por el mundo una revolución cultural y demográfica de primera magnitud: la agricultura y la ganadería. Aunque marginales, todavía hoy quedan residuos de algunas culturas basadas en la recolección y la caza, en las que la agricultura apenas juega papel económico alguno; se trata de poblaciones humanas que habitan en regiones en las que las circunstancias ecológicas, demográficas, históricas, etc no han permitido o fomentado los cultivos o la cría de ganado; entre estas poblaciones (hoy en franca regresión) están algunos pigmeos de África central, ciertas poblaciones esquimales o algunas tribus de aborígenes australianos o neoguineanos.

La arqueología, la arqueozoología y la etnobiología han permitido rescatar y difundir el particular conocimiento que algunos de estos pueblos de cazadoresrecolectores tienen o tuvieron acerca de los animales y plantas con los que han interactuado durante milenios.

La revolución neolítica supuso una creciente independencia de los recursos que como caza, pesca o frutos silvestres, ofrecía la naturaleza. El hombre aprende y perfecciona las técnicas agrícolas y ganaderas, e incorpora a su acervo cultural clasificaciones diversas de animales y plantas, a menudo influidas por su utilidad o aprovechamiento y, a veces, con un carácter mágico o religioso. Así al menos inducen a pensar los restos de las más antiguas civilizaciones que han legado testimonios escritos, como los sumerios o los egipcios (III milenio a. de C.). 
A pesar de la disparidad de culturas y de las enormes diferencias ecológicas entre unas poblaciones humanas y otras, los investigadores han podido establecer unos principios generales en las clasificaciones que de animales y plantas hacen pueblos muy diferentes y que me permito transcribir a continuación, en lo que se ha llamado taxonomía y nomenclatura etnobiológicas.

Los principios generales de la taxonomía y nomenclatura etnobiológicas pueden resumirse en los siguientes ${ }^{1}$ :

\section{CATEGORIZACIÓN}

1.- En los sistemas de clasificación etnobiológicos, se da reconocimiento conceptual a una parte de la flora y la fauna existente. Esta parte comprende las especies biológicamente más llamativas del medio natural local.

2.- Los sistemas de clasificación etnobiológicos se basan en un principio en las afinidades que observan los humanos entre los propios taxones, con independencia del significado cultural potencial o real de estos taxones.

3.- Los sistemas de clasificación etnobiológicos se organizan conceptualmente en una ligera estructura jerárquica.

4.- Los taxones reconocidos quedan distribuidos en cuatro a seis categorías etnobiológicas mutuamente excluyentes, en las que los taxones comparten grados de variación interna similares, y están separados unos de otros por diferencias de tamaño comparable. Las seis categorías universales son: reino, forma vital, categoría intermedia, género, especie y variedad.

5.- A lo largo de los sistemas de clasificación etnobiológica, los taxones de cada categoría muestran unas marcadas semejanzas tanto en sus números relativos, como en sus rangos biológicos.

6.- Los taxones etnobiológicos de la categoría genérica o específica muestran una estructura interna en la que algunos miembros son considerados prototípicos del taxón, mientras que otros parecen menos típicos de dicha categoría.

7.- Una sustancial mayoría de taxones etnobiológicos se corresponden de cerca en contenido con taxones reconocidos independientemente por la botánica y la zoología occidentales, con el máximo grado de coincidencia en los taxones del nivel genérico. Con frecuencia los taxones de categoría intermedia corresponden a porciones de familias biológicas reconocidas. La menor correspondencia con taxones biológicos reconocidos se da en los taxones de las categorías subgenéricas y de forma vital.

I Berlin, B. (1992). Ethnobiological classification. Princeton, Princeton University Press, 335 pp. 


\section{NOMENCLATURA}

1.- Los taxones de las categorías "Reino" e "Intermedia" no suelen denominarse. A veces se encuentran taxones de la categoría "forma vital" disimulados, cuyo nombre (cuando lo lleva) muestra relaciones polisémicas con taxones de categoría subordinada.

2.- Los nombres de las plantas y de los animales muestran una estructura léxica de uno o dos tipos léxicos universales, que pueden denominarse nombres primarios o secundarios de plantas y animales. Los nombres primarios son de tres tipos: simples, productivos y no productivos. Los nombres secundarios suelen especificar alguna característica de un taxón de rango superior y al que están referidos.

3.- Se puede observar una relación entre los nombres de los taxones y su categoría. Las categorías "forma vital" y "género" suelen ser nombres primarios; los taxones subgenéricos suelen llevar nombres secundarios.

4.- Hay dos condiciones bien conocidas bajo las que los taxones subgenéricos pueden llevar nombres primarios; la primera sucede cuando el nombre subgenérico prototípico es polisémico con el taxón de rango superior; la segunda sucede cuando el nombre subgenérico no prototípico se refiere a taxones subgenéricos de gran importancia cultural.

5.- Con frecuencia, la nomenclatura etnobiológica está relacionada con características morfológicas, ecológicas o de comportamiento, que no son arbitrarias.

Un ejemplo curioso de este último aspecto de la nomenclatura etnobiológica, lo hallamos en las denominaciones de las mariposas en náhuatl. En la lengua azteca principal, el náhuatl, mariposa se dice papalotl, de donde ha pasado al español como papalote, vocablo que en Méjico y Cuba designa a las cometas (Silvio Rodríguez tiene una canción con ese nombre). Con papalotl se formaban muchas palabras compuestas, para nombrar diferentes especies: Ixtacpapalotl, mariposa blanca (piérido), Matlalpapalotl, mariposa azul (género Morpho), Matlalpapaloton, mariposas azules pequeñas (licénidos), Tzonicanpapalotl, mariposa que se para de cabeza (géneros Myscelia, Prepona y Smyrna, que hacen justamente eso), Tzahuanpapalotl, mariposa pájaro (esfíngido), y muchas otras ${ }^{2}$. Sorprende el hecho, supongo que casual, de que la palabra que entre los aztecas significaba mariposa se parezca más al latín papilio, que la propia palabra española ${ }^{3}$.

2 DE LA MAZA, R. (1987). Mariposas mexicanas. Fondo de Cultura Económica. México.

3 VIEJO, J.L. (1994). "Mitos y Leyendas sobre las mariposas". Quercus, vol. 100, pp. 56-57. 


\section{EL ANTROPOCENTRISMO EN LA TAXONOMÍA CIENTÍFICA.}

Con independencia de las clasificaciones típicamente "populares", la historia de la ciencia reconoce a Aristóteles (384-322 a. de C.) como el fundador de la taxonomía. La mayor parte de las clasificaciones de animales y plantas propuestas por la ciencia "oficial" hasta Linneo estaban basadas de cerca en las ideas aristotélicas.

Aristóteles dividía los seres vivos $(\psi v \chi \alpha \hat{i})$ en animales $(\zeta \hat{\omega} \alpha)$ y vegetales $(\phi \cup \tau \dot{\alpha})$. Los animales quedaban divididos en racionales (el hombre) e irracionales (el resto); éstos últimos eran separados en dos grupos: los provistos de sangre $(\grave{\varepsilon} v \alpha \imath \mu \alpha)$ y los que carecen de ella $(\ddot{\alpha} v \alpha \imath \mu \alpha)$. Los animales con sangre se dividían en cuadrúpedos vivíparos (que venían a ser los mamíferos), cuadrúpedos ovíparos (los reptiles y los anfibios), aves, peces y serpientes. Los animales exanguies estaban divididos en moluscos (los cefalópodos solamente), testáceos (los gasterópodos, bivalvos y otros invertebrados con caparazón), insectos (los "éntoma", o artrópodos no crustáceos, además de los anélidos) y crustáceos.

La clasificación aristotélica de los animales se mantuvo a lo largo de más de dos milenios de historia de la ciencia sin apenas cambios. Incluso en la obra de Ray (1627-1705) se advierte una marcada influencia aristotélica, a pesar de los avances que en anatomía y fisiología se habían logrado en el Renacimiento.

El sistema aristotélico era congruente con la lógica conceptual platónica, en la clasificación de los animales desde las categorías de rango superior, hasta las especies particulares, que se incluían en géneros agrupados en función de aspectos ecológicos, más que anatómicos. Sin embargo Linneo (1707-1778) deja de lado los criterios ecológicos y utiliza principalmente los criterios anatómicos y fisiológicos en la clasificación de los animales. En la primera edición de su Systema Naturae (1735), los animales se dividen en Quadrupedia, Aves, Amphibia, Pisces, Insecta y Vermes. En la décima edición (1758), desaparecen los Quadrupedia, que son sustituidos por los Mammalia, y Linneo aplica la nomenclatura binomial a todas las especies animales conocidas, e incluye entre ellas al hombre. Veamos en síntesis la clasificación zoológica linneana ${ }^{4}$ :

\section{MAMMALIA}

Primates: Hombre (Homo), monos (Simia), lemures (Lemur) y murciélagos (Vespertilia).

Bruta: Elefantes, manatíes, perezosos, pangolines, etc.

Ferae: Focas, perros, lobos, hienas, zorros, osos, etc.

Bestiae: Cerdos, armadillos, erizos, topos, musarañas, etc.

4 Linnaeus, C. (1758). Systema Naturae. Regnum Animale. Holmiae, 10 ed., 824 pp. 
Glires: Rinocerontes, liebres, conejos, castores, ratones, ardillas, etc.

Pecora: Camellos, llamas, jirafas, ciervos, cabras, ovejas, gacelas, vacas, etc.

Bellua: Caballo, burro, cebra, hipopótamo, etc.

Cetae: Ballenas, marsopas, delfines, etc.

\section{AVES}

Accipiters: Buitres, halcones, águilas, búhos, etc.

Picae: Loros, tucanes, cornejas, cuclillos, abejarucos, etc.

Anseres: Patos, cisnes, gansos, alcas, petreles, pelícanos, albatros, somormujos, etc.

Grullae: Flamencos, espátulas, grullas, avoceta, avutarda, avestruz, etc.

Gallinae: Gallina, faisán, etc.

Passeres: Palomas, tórtolas, alondras, estorninos, pinzones, herrerillos, golondrinas, etc.

\section{AMPHIBIA}

Reptilia: Tortugas, galápagos, lagartos, ranas, etc.

Serpentes: Serpientes.

Nantes: Rayas, esturión, etc.

\section{PISCES}

Apoda: Anguilas.

Iugulares: Bacalao, rubios, etc.

Thoracici: Peces planos, góbidos, etc.

Abdominales: Salmón, trucha, lucio, arenque, etc.

Branchiostegi: Peces globo, peces ballesta, etc.

\section{INSECTA}

Coleoptera: Escarabajos, tijeretas, saltamontes, cucarachas, mántidos, fásmidos, etc.

Lepidoptera: Mariposas y polillas.

Neuroptera: Neurópteros, efemerópteros, etc.

Hymenoptera: Hormigas, abejas y otros himenópteros.

Diptera: Moscas y otros dípteros.

Aptera: Apterigotos, piojos, pulgas, pseudoescorpiones, opiliones, arañas, garrapatas. 


\section{VERMES}

Intestina: Anélidos, trematodos, cestodos, etc.

Mollusca: Gasterópodos sin concha, cefalópodos, equinodermos, etc.

Testacea: Crustáceos, bivalvos, gasterópodos con concha, poliquetos sésiles, etc.

Lithophyta: Caracoles, briozoos, hidrocorales, etc.

Zoophyta: Hidroideos, briozoos, etc.

En lo que concierne al motivo principal de este trabajo, hemos de resaltar que Linneo incluye al hombre en su sistema, en apariencia como un animal más. Eso sí, para dar preeminencia al grupo zoológico en el que lo sitúa, denomina al orden Primates, "los primeros". Con ser un avance respecto a las clasificaciones precedentes, no podemos afirmar que el sistema linneano suponga un drástico cambio en la concepción antropocéntrica de los animales, como era la norma en la ciencia de la época (y aun de los dos siglos siguientes), como queda de manifiesto, por ejemplo en Buffon (1707-1788) quien en su Histoire Naturelle (1749-1788) sitúa al hombre en la cúspide de la "escala de los seres", aunque destaca la enorme distancia entre los animales y el hombre.

Un cambio sutil, aunque de gran alcance, se introduce en el panorama taxonómico con Lamarck (1744-1829), que incluye por primera vez al hombre en la "escala natural" y, aunque con igual preeminencia que sus predecesores Linneo y Buffon, lo considera el producto final de la evolución; la hipótesis que plantea Lamarck en Philosophie Zoologique (1809) sobre el proceso evolutivo humano es asombrosamente moderna:

\footnotetext{
"Efectivamente, si una raza cualquiera de cuadrumanos, sobre todo la más perfeccionada de ellas, perdiese, por la necesidad de las circunstancias, el hábito de trepar sobre los árboles y de abarcar las ramas con sus pies, así como con las manos, para agarrarse á ellas, y si los individuos de esta raza, durante una larga sucesión de generaciones, se hubieran visto obligados á no servirse de sus pies más que para andar y cesasen de emplear en este ejercicio sus manos de igual manera que los pies, es indudable, según las observaciones expuestas en el capítulo VII, que tales cuadrumanos se transformarían por fin en bimanos, y que los pulgares de sus pies no cesarían de ser separados de los dedos, no sirviéndoles ya dichos miembros más que para marchar"5.
}

Para Lamarck, el hombre es la culminación del proceso evolutivo y "la más alta perfección que la naturaleza puede alcanzar", de tal modo que cuanto más se aproxime la organización animal al hombre, más perfecta será aquélla.

5 Lamarck, J.B. (1809). Philosophie zoologique. Valencia, primera versión en español de Sempere y Cia. Editores, 240 pp., cita en p. 234. 
En cuanto a la organización taxonómica general de los animales, Lamarck propone una clasificación algo más compleja que la de Linneo, pero también teñida de un curioso antropocentrismo. Los animales se dividen en tres grandes grupos, según su "grado de inteligencia": Apáticos, Sensibles e Inteligentes; los dos primeros los agrupa en los "Invertebrados" (término acuñado por el propio Lamarck) y el tercero corresponde a los "Vertebrados". Entre los Apáticos están los infusorios, los pólipos, los radiados y los gusanos; entre los Sensibles están los insectos, los arácnidos, los crustáceos, los anélidos, los cirrípedos y los moluscos. Los Inteligentes son los peces, los reptiles, las aves y los mamíferos ${ }^{6}$.

Cuvier (1769-1832) propone en Nouveau rapprochement à établir entre les classes qui composent le règne animal (1812), una clasificación zoológica más completa, en función del tipo arquitectónico de los animales: Vertebrados, Articulados, Moluscos y Radiados. Dentro de los Vertebrados incluye los mamíferos, las aves, los reptiles y los peces. La clasificación de los mamíferos que ofrece Cuvier está expresada en forma de clave dicotómica, aunque no por ello exenta de la habitual tendencia a la distinción particular del hombre. Dicha clasificación es la siguiente:

I. Mamíferos provistos de cuatro miembros propios para la marcha.

A. Unguiculados.

1. Tres clases de dientes.

a. Sin bolsa mamaria.

* Solamente los pulgares de los miembros superiores oponibles: Bimanos (Hombre).

*** Pulgares de los cuatro miembros oponibles: Cuadrumanos (monos).

***k Pulgares no oponibles: Carnívoros (quirópteros, insectívoros y carnívoros s.s.).

b. Con bolsa mamaria: Marsupiales.

2. Dos clases de dientes como máximo.

a. Incisivos y molares. Sin caninos: Roedores.

b. Sólo molares: Desdentados (desdentados ordinarios y monotremas).

B. Ungulados.

1. Estómago simple: Paquidermos (proboscídeos, paquidermos ordinarios y solípedos).

2. Estómago complicado, propio para la rumia: Rumiantes.

6 LAmarCK, J.B. (1815). Histoire naturelle des animaux sans vertèbres. Paris, Verdière. 
II. Mamíferos provistos de dos miembros solamente, los anteriores, que están dispuestos en forma de remo: Cetáceos.

Merece la pena señalar que Cuvier, fundador de la anatomía comparada, elaborara una clasificación tan artificiosa, en la que persiste la obstinación en separar a los seres humanos del resto de los mamíferos, incluso recurriendo a caracteres tan poco relevantes para una separación en órdenes, como la posición bípeda y la presencia de pulgares oponibles.

Hubo incluso naturalistas que para resaltar las diferencias entre el hombre y el resto de mamíferos, separaron a aquél en una subclase distinta ¡e incluso un reino aparte!.

En numerosas clasificaciones mastozoológicas del siglo XIX se conserva la separación ordinal del hombre y los simios, tal y como la plantea Cuvier, de modo que apenas se utiliza el nombre linneano de Primates. Así, el famoso zoólogo francés Paul Gervais separa al hombre de simios y lemures, y proclama la preeminencia de los seres humanos dentro de los mamíferos, con este encantador antropocentrismo:

\begin{abstract}
"L'harmonie des proportions du corps humain, la beauté de ses lignes; sa station droite (situs erectus) et les dispositions qui rendent cette station possible; la tête si bien équilibrée au-dessus du tronc, et la dignité du visage (os sublime) portant ses regards au ciel (coelum tueri jussit), au lieu de les abaisser vers le sol comme le font les animaux (pronaque dum. spectent caetera animalia terram); l'élévation du front et l'ampleur du crâne, traduisant au dehors le grand développement du cerveau de l'homme, c'est-à-dire de son centre principal d'innervation affecté aux fonctions de relation; la perfection de ses mains, qui, étant à la fois des organes de tact et de préhension, deviennent les instruments les plus délicats de son intelligence; la conformation de ses membres inférieures, réservés pour la marche, et dont le pouce n'est pas opposable aux autres orteils; toutes ces particularités extérieures, dont on pourrait augmenter encore la liste, font de l'homme une espèce bien différente de celles qui méritent la dénomination de singes; elles ne permettent pas davantage de l'associer génériquement à des animaux de cette famille, pas même à ceux auxquels le grand naturaliste suédois, par une application évidemment exagérée de ses propres principes de classification, n'avait pas craint d'étendre le nom d'hommes" [en alusión al nombre que Linneo dio al orangután, Homo satyrus, al chimpancé, H. troglodytes, y al gibón, $H$. lar, todos dentro del mismo género que los seres humanos] $]^{7}$.
\end{abstract}

El taxón Bimana de Cuvier (aunque previamente propuesto por Blumenbach en 1791) aparece en numerosas clasificaciones, para separar al hombre en un orden diferente del resto de mamíferos, y en particular de los Primates de Linneo, a los que 334.

7 Gervals, P. (1877). Éléments de Zoologie. Paris, Librairie Hachette et Cie., 643 pp., cita en p. 
se les suele aplicar el nombre de Quadrumana. Así, por ejemplo, se recoge en las obras de Dumeril (1806), Milne-Edwars (1834), Leunis (1844), Vogt y Yung (1888), Selys-Longchamps (1842) entre otros muchos naturalistas. Y así se imparte en las universidades españolas en el último tercio del siglo $\mathrm{XIX}^{8}$, aunque Graells en su obra Fauna Mastodológica Ibérica (1897) resucita el orden linneano de Primates e incluye en él al hombre. Por otra parte, el ambiente científico de la época en España está teñido de prejuicios racistas, como queda de manifiesto en este párrafo extraído del manual de zoología de Pérez Arcas, y referido a la descripción "biológica" de la raza negra:

"La raza negra está caracterizada por el color de la tez negro ó negruzco, el cabello corto y rizado, de aspecto lanoso, la nariz chata, los labios gruesos, y el ángulo facial de $70^{\circ}$ á $75^{\circ}$ (fig. 79 y 80). Los individuos que componen esta raza, tienen la inteligencia menos desarrollada que las anteriores, y las sociedades que forman, se encuentran todavía muy atrasadas en el camino de la civilización"').

Sin embargo, la tendencia más claramente antropocéntrica respecto a la clasificación zoológica del hombre se quiebra a partir de Darwin, tanto por la publicación de El origen de las especies (1859), como (y sobre todo) por la de El origen del Hombre y la selección en relación al sexo (1871); en este último libro, Darwin enumera y describe las pruebas que a su juicio demuestran que el Hombre desciende de una forma inferior (en palabras del propio Darwin), compara las estructuras anatómicas y las facultades mentales del hombre y de los demás animales y destaca las afinidades de los seres humanos con el resto de los primates; en la segunda parte de este libro, Charles Darwin describe de modo prolijo los principios de la selección sexual a lo largo del reino animal y su importancia en la evolución de las especies, seres humanos incluidos. Esta segunda parte es tan meritoria en sus descripciones, como discutible (y aún errónea) en sus conclusiones, a la luz de la Biología de un siglo después.

Tal y como señala Mayr, el darwinismo supuso la mayor de las revoluciones científicas; no se trataba simplemente de la sustitución de una teoría científica (la inmutabilidad de las especies) por otra, sino que además exigía un replanteamiento del concepto y del papel del hombre en el mundo; desde el punto de vista filosófico, la revolución darwiniana implicó la sustitución de un mundo estático por uno dinámico y cambiante, la refutación del creacionismo y de la teleología cósmica, la abo-

8 Véase: PÉrez ARCAS, L. (1861). Elementos de Zoología. Madrid, Imprenta de Gabriel Alhambra, 543 pp., MARTínez SÁEZ, F. (1879). Distribución metódica de los Vertebrados. Madrid, Imprenta de Fortanet, 528 pp. y Bolívar, I y S. CALderón, (1900). Nuevos elementos de Historia Natural. Madrid, Establecimiento tipográfico de Fortanet. $470 \mathrm{pp}$.

9 Pérez ArCas, L. (1861) p. 154. 
lición del antropocentrismo absoluto al aplicar al hombre los principios evolutivos generales, y la explicación "heterodoxa" (desde el punto de vista de los dogmas cristianos) de la aparición y evolución de los seres vivos mediante procesos materialistas, entre otras trascendentes implicaciones ${ }^{10}$.

Que la obra de Darwin conmoviera el pensamiento biológico no significa que el antropocentrismo desapareciera de la zoología y aun de las teorías evolutivas. En unos casos por abierta oposición al darwinismo, y en otros por una interpretación sesgada de la teoría de la selección natural, el antropocentrismo biológico va aún a prosperar en ciertos sectores de las sociedades occidentales y, en algún momento, va a servir de pesado lastre para el progreso cultural de la humanidad, como ha ocurrido con el empeño en la enseñanza del creacionismo frente a las teorías evolutivas en los EE. UU. ("el juicio de Scopes" y otras controversias que relata Gould ${ }^{\prime \prime}$ )y la interpretación acérrima del darwinismo social. Esta corriente de pensamiento, aparecida a finales del siglo pasado promovida por Herbert Spencer, sirvió de base para justificar el racismo y aun para proponer una llamada eugenética humana, mediante técnicas éticamente intolerables de "zootecnia humana"12.

A veces el prejuicio étnico se ha disfrazado de taxonomía científica, para clasificar en taxones diferentes a los seres humanos en función, por supuesto, de las creencias y hábitos de índole cultural. El propio Darwin da un repaso al estado de esta cuestión en la época y expone tanto testimonios de naturalistas defensores de la heterogeneidad específica de los seres humanos, como de los defensores de la unicidad de la especie. Él mismo se incluye entre estos últimos, aunque atribuye a las razas humanas un carácter subespecífico:

"Pero, desde que obtuvo el rango de naturaleza humana, se ha separado, desviándose en distintas razas, o, como mejor pudiéramos llamarlas, subespecies"13,

si bien manifiesta explícitamente la dificultad de establecer límites cntre ellas. Otros naturalistas no eran tan prudentes, y manifestaban abiertamente su aversión a ser incluidos en la misma especie que los negros, como Leo Dufour, que rechazaba no sólo la hermandad específica con ellos, sino incluso el parentesco de primos ${ }^{14}$. El

10 MAYR, E. (1982). The Growth of Biological Thought. Cambridge, Massachusetts, The Belkanp Press of Harvard University Press, 974 pp.

$"$ Gould, S.J. (1993). "Brontosaurus" y la nalga del ministro. Barcelona, Crítica, 357 pp.

12 JAHN, I., LOTHER, R. y K. SENGLAUB (1989). Historia de la Biología. Barcelona, Labor, 780 pp.

13 DARWIN, CH. (1871). El origen del hombre y la selección en relación al sexo. Madrid, versión en español de Ediciones Ibéricas, 2 vols., 402 y 430 pp., respectivamente, cita en vol. 2, p. 389.

14 Citado por Graells, M.P. (1897). Fauna Mastodológica Ibérica. Madrid, Memorias de la Real Academia de Ciencias Exactas, Físicas y Naturales, tomo XVII, 806 pp., cita en p. 149. 
propio Graells, cuarenta años después de El origen de las especies, sigue sosteniendo un creacionismo rígido que, en el caso del hombre, le lleva a incluirlo en diferentes especies, tal y como las percibió Moisés: los blancos (cuyo padre fue Jafet), los negros (cuyo padre fue Cam) y los amarillos (cuyo padre fue Sem); en el caso de los habitantes de la península Ibérica, reconoce la mezcolanza de supuestas razas, cuya enumeración no me resisto a mencionar: Homo caucasicus, los blancos, a los que pertenecen los taxones (la verdad, de categoría imprecisa) Homo pelasgius (los griegos), Homo celticus (los celtas), Homo arabicus (los árabes), Homo germanicus var. teutone (los godos) y Homo germanicus var. slavonicus (los gitanos); a estos últimos dedica extensas descripciones teñidas de prejuicios y de racismo:

\footnotetext{
"En general, sin oficio conocido, son de costumbres con frecuencia depravadas, viviendo promiscuados entre sí y con las bestias que llevan á vender á las ferias. Muy diestros en la rapiña, la ejercen de modos variados, no con violencias, pero sí con engaños, unas veces vendiendo por buenos, burros remendados, ó merodeando de noche en los despoblados las haciendas poco vigiladas" 15 .
}

\section{EL ANTROPOCENTRISMO EN LA PALEONTOLOGÍA HUMANA.}

Por fortuna, los descubrimientos paleontológicos y los avances de la biología humana han ido desentrañando algunos de los problemas referidos al origen del hombre y de las razas humanas, y desterrando algunos de los rasgos antropocéntricos que caracterizaron los albores de la Antropología física, si bien el camino recorrido en el último siglo no ha sido ni lineal, ni uniforme. Al margen de aspectos etnocéntricos que mencionaré después, el estudio de los orígenes de la humanidad, su evolución y su destino han estado con frecuencia teñidos de lo que Leakey y Lewin han llamado "el principio antrópico"16. Wallace, proponente junto a Darwin de la teoría de la selección natural, consideraba que la mente humana tenía un sentido moral que excluía al hombre de la corriente evolutiva del resto de los primates, pues no podría si no entenderse la perfección de determinadas cualidades físicas; Wallace creía que la evolución humana era dirigida en una dirección y con una finalidad concretas. Paleoantropólogos como Robert Broom, a mediados de siglo, afirmaban que

"parece como si buena parte de la evolución hubiera estado planificada y pensada para desembocar en el hombre, y en otros animales y plantas, para hacer del mundo un lugar ade-

15 Graells, M.P. (1897) pp. 153-154, véase también las pp. 617-624.

16 LEAKEY, R. y R. Lewin (1994). Nuestros orígenes. Barcelona, Crítica, 300 pp. 
cuado para que el hombre pudiera vivir en él. Resulta difícil creer que el simio pensante, de enorme cerebro, fue un mero accidente" 17 .

En este brevísimo repaso del antropocentrismo en el estudio sobre la evolución humana no podría faltar una mención a Teilhard de Chardin (1881-1950). Deseoso de armonizar fe y ciencia, el padre Teilhard propone una visión evolucionista del cosmos, según la cual la vida habría surgido en nuestro planeta como una etapa más de la evolución cósmica:

"La Vida no es una anomalía curiosa, floreciente esporádicamente sobre la Materia, sino que la Vida es exageración privilegiada de una propiedad cósmica universal; la Vida no es un epifenómeno, sino la esencia misma del Fenómeno"18.

Según Teilhard, la evolución "arrastra" a los seres vivos desde su origen, a partir de un estado prebiótico, la trofosfera, hacia la biosfera y la aparición del hombre, quien, en una espiral evolutiva ascendente (la ortogénesis), alcanzará un nuevo estadio de rango superior, la noosfera, o esfera de la reflexión y la conciencia. Según el antropólogo jesuita, a partir del Homo sapiens actual se desarrollará un ser ultrahumano, cercano al punto Omega, vecino inmediato de Dios ${ }^{19}$. Vemos pues en el padre Teilhard un antropocentrismo sin límite, por el que toda la evolución, tanto cósmica, como biológica, tiene razón de ser en tanto culmina en el hombre ("la vida culmina en el hombre, como la energía culmina en la vida").

El hombre como culminación del proceso evolutivo ha sido un constante prejuicio de la ciencia y de la cultura occidental, expresado tanto en términos evolutivos explícitos, como en la posición que, junto a los demás primates, se le asigna en tratados de zoología y textos en general. Un buen ejemplo de lo primero, y en la mejor tradición teilhardiana, está en el libro de Crusafont, Meléndez y Aguirre, La Evolución (1974), en el que puede leerse:

"En la cumbre de la evolución de los Primates -que es la cumbre de toda la Evoluciónencontramos los Catarrinos, los cuales, aparte de los Cercopitécidos, que abarcan los Simios caudatos, dan lugar, finalmente, a los Antropomorfos, que en la Sistemática agrupan a los Simios superiores y a los Homínidos"20.

\footnotetext{
17 LEAKEY, R y R. LEWIN, (1994) p. 275.

18 Teilhard De Chardin, P. (1962). El grupo zoológico humano. Madrid, Taurus, 145 pp., cita en p. 22.

19 Tellhard De Chardin, P. (1963). El fenómeno humano. Madrid, Taurus, 379 pp.

20 Crusafont, M., Meléndez, B y E. Aguirre (1994). La evolución. Madrid, Biblioteca de Autores Cristianos, 1159 pp., cita en p. 544.
} 


\section{JOSÉ LUIS VIEJO MONTESINOS}

Aunque somero, cualquier repaso a tratados de zoología o a textos escolares de Ciencias Naturales, sean antiguos o modernos, nos ofrece un marcado sesgo antropocéntrico con respecto a la posición del grupo taxonómico humano (Primates, Bimanos e incluso la familia Homínidos) que o bien se sitúan los primeros (como ocurre en tratados antiguos como los de Gervais, 1877; Martínez Sáez, 1879; Graells, 1897), quizá como expresión de preeminencia, o bien los últimos (como ocurre en tratados más modernos, v. gr. D'Ancona, 1970; Hickman \& AL., 1986)21 quizá como implícito reconocimiento de la aludida culminación.

Tras superar, no sin traumas, la aceptación casi universal (en el pensamiento científico) de la realidad evolutiva, la Iglesia Católica acogió con cierto alivio la compatibilidad entre la concepción cristiana de la naturaleza humana y el origen biológico de la especie, tal y como iba desprendiéndose de los sucesivos y numerosos hallazgos científicos. Pero dicha compatibilidad está basada en una idea de progreso, de dirección y sentido hacia algo que cada vez más biólogos ponen en duda. Esta idea de progreso en la evolución orgánica ha sido un prejuicio constante en los textos científicos, al menos desde Lamarck. Los árboles filogenéticos de los primeros seguidores de Darwin (Haeckel y otros) comenzaron a diseñar y a acuñar lo que Gould llama "el cono de diversidad creciente"22, es decir, un árbol filogenético en el que, con el tiempo, las ramas se iban haciendo más numerosas y daban la sensación de que el momento presente es el de la mayor diversidad posible. Revisiones globales de faunas pretéritas ponen en duda este principio de la diversidad creciente y aun de la idea de progreso, como por ejemplo, la súbita aparición en el Cámbrico de decenas de tipos de organización diferentes. Esta nueva perspectiva, de modo indisoluble asociada al principio de contingencia, asesta un nuevo golpe a una concepción antropocéntrica del mundo biológico.

\section{ETNOCENTRISMO, TAXONOMÍA Y NOMENCLATURA.}

Decía al principio que clasificar no es tarea inocente, pues toda ordenación lleva implícito un criterio, una opinión. Pero más subjetiva aún es la labor de denominar los taxones, de buscar un nombre con el que designar las especies, los géneros y las familias. A partir del Systema Naturae de Linneo, edición de 1758, tanto la zoología como la botánica adquieren un patrón nomenclatural que va ser la pauta fundamental de la taxonomía y la nomenclatura hasta la fecha.

21 D'ANCONA, H. (1970). Tratado de Zoología. Barcelona, Labor, 2 vols. y HicKMAN, C.P., ROBERTS, L.S. y F.M. HICKMAN (1986). Zoología, Principios integrales, Madrid, Interamericana, $7^{\mathrm{a}}$ ed., $1011 \mathrm{pp}$.

22 Gould, S.J. (1991). La vida maravillosa. Barcelona, Crítica, 357 pp 


\section{EL HOMBRE COMO ANIMAL: EL ANTROPOCENTRISMO EN LA ZOOLOGÍA}

Durante el siglo XIX los problemas de nomenclatura no se mostraron especialmente graves, a pesar del exponencial crecimiento de los taxones descritos; pero a medida que se iba engrosando la nómina de taxones, los naturalistas se encontraron con un maremágnum de nombres, sinónimos (dos nombres para el mismo taxón), homónimos (dos taxones con el mismo nombre) y otros problemas de nomenclatura sin una norma escrita concreta que ordenase la denominación científica de los seres vivos. Esa necesidad impulsó a los zoólogos a crear un cuerpo legislativo particular, que cuajó en el Congreso Internacional de Zoología, celebrado en Londres en 1958, que propuso el primer Código Internacional de Nomenclatura Zoológica, cuya primera edición se publicó en 1961. A partir de aquí, la nomenclatura zoológica ha entrado en una fase algo más ordenada, pero tampoco exenta de dificultades, habida cuenta del ingente número de taxones animales que hay descritos (sólo de especies se conocen más de un millón) y los aún más numerosos por describir (se habla de hasta treinta millones de especies).

Pues bien, los nombres científicos de los animales comienzan por tener ya el sesgo cultural del latín. El código internacional de nomenclatura zoológica señala que los nombres de los taxones de las categorías que le conciernen han de ser palabras de origen latino o latinizadas, escritas en el alfabeto latino (con el añadido de la $\mathrm{j}$, la $\mathrm{k}$, la w y la y) y, en su caso, declinadas y concordadas al modo latino. Debo reconocer que este sesgo hacia la cultura latina es un notable avance y un gran beneficio para el mutuo entendimiento de los científicos. Que haya supuesto un excelente instrumento de comprensión internacional, no quita para que debamos señalar aquí el cierto "etnocentrismo" con el que la nomenclatura linneana ha impregnado la zoología. La cultura clásica greco-latina ha quedado inequívocamente unida a los nombres de los animales, y con ella los prejuicios, usos y costumbres de los primeros zoólogos postlinneanos, como sensata y humildemente reconoce J. Chester Bradley en el prólogo a la primera edición del Código Internacional de Nomenclatura Zoológica (1961):

\footnotetext{
"Like all language, zoological nomenclature reflects the history of those who have produced it, and is the result of varying and conflicting practices. Some of our nomenclatural usage has been the result of ignorance, of vanity, obstinate insistence on following individual predilections, much, like that of language in general, of national customs, prides, and prejudices"23.
}

Como señala Alvarado, aparte de los nombres vulgares latinos que Linneo rescató para denominar a animales más o menos corrientes (Bos, para el buey; Canis, para el

2.3 C.I.N.Z. (1985). Code International de Nomenclature Zoologique. London, International Trust for Zoological Nomenclature \& British Museum (Natural History ), $3^{\mathrm{a}}$ ed., $338 \mathrm{pp}$. 


\section{JOSÉ LUIS VIEJO MONTESINOS}

perro; Felis, para el gato; Equus, para el caballo; Papilio, para las mariposas), la rica tradición linneana extrajo de la mitología bellos nombres, a veces alegóricos, a veces no, que fueron aplicándose a animales desconocidos en la antiguiedad, como el ctenóforo Beroe, nombre de una matrona troyana tomado de la Eneida, el crustáceo Palinurus, nombre del piloto de Eneas, o el lepidóptero Danaus, nombre de un nieto de Poseidón ${ }^{24}$. Otras veces se compusieron nombres con raíces y desinencias griegas o latinas que aludían a alguna característica particular del taxón denominado (en uso de la lícita subjetividad del taxónomo), como Mycetophagus (literalmente: el que come hongos) para unos coleópteros que comen hongos, o loricíferos (literalmente: portador de loriga) para un tronco de invertebrados diminutos cubiertos de plaquitas, Ornithoteuthis (literalmente: calamar pájaro) para unos calamares, Chiropotes (literalmente: "el que bebe con la mano") para unos monos cébidos sudamericanos.

Bien es cierto que el Código Internacional de Nomenclatura Zoológica no excluye el uso de palabras extraídas de otras lenguas que el latín (ya hemos visto algunas raíces griegas); así son perfectamente utilizables palabras como opossum, que es de origen algonquino, Abudefduf, del árabe, o incluso combinaciones de letras a modo de juego, como los géneros de isópodos Cirolana, Lanocira, Rocinela, Nerocila, Anilocra y otros (la mujer del naturalista descriptor, W.E. Leach, se llamaba Carolina, obviamente).

La elección de nombres para nuevos taxones a veces refleja una apreciable subjetividad, cuando no un prejuicio. El C.I.N.Z. establece un código de ética (Apéndice A) y unas recomendaciones (Apéndice D) que desaconsejan el uso de nombres malsonantes, ofensivos o que impliquen algún tipo de opinión política; sin embargo algunos zoólogos bordean estas recomendaciones y han introducido nombres como Marichisme, Pollychisme, Peggichisme, Dolychisme y Florichisme, que son géneros de chinches, y que pronunciados al modo inglés suenan como "Mary bésame" ("Mary, kiss me"), "Polly bésame", etc.

En otras ocasiones el antropocentrismo en la nomenclatura no viene sólo del nombre elegido en sí, sino también del subjetivismo e incluso del mito al que alude el nombre. El lepidóptero esfíngido Acherontia atropos tiene en la parte dorsal del tórax un conjunto de manchas que se asemeja a una calavera (humana, por supuesto); a esto se une el sonido que es capaz de producir mediante la expulsión forzada de aire; todo ello ha forjado la creencia de que este insecto trae mal aguiero. Según la mitología griega, Aqueronte era el nombre del río de los infiernos, cuyas aguas negras tenían que cruzar en la barca de Caronte todos los muertos; Átropos era una de las tres Parcas, encargadas de cortar el hilo que une al hombre con la vida.

\footnotetext{
24 Alvarado, R. (1982). De nomenclatura juxta praeceptum aut consensu biologorum. Discurso de ingreso en la Real Academia Española de la Lengua, Madrid, 131 pp.
} 
De subjetivo también podemos calificar el criterio de denominar a los taxones con términos geográficos (en general topónimos) alusivos a su área de distribución; como en otras ocasiones, la subjetividad es la antesala del prejuicio. Algunos ejemplos nos servirán para comprender esta circunstancia. La culebra bastarda Malpolon monspessulanus recibe el nombre específico en alusión a Montpellier, cuando su área de distribución incluye la mayor parte de la península Ibérica, costa mediterránea francesa, península Balcánica, área occidental del Caspio y también otras zonas de Asia occidental y del norte de África; ¡menos mal que sí que está en Montpellier!. La famosa falena Graellsia isabelae, descrita por M.P. Graells en 1849, es un lepidóptero repartido por muchos pinares maduros ibéricos de la mitad oriental de la península; hasta 1922 no se descubrió también en Francia (en los Hautes-Alpes), en circunstancias aún hoy controvertidas ${ }^{25}$ : la población francesa se incluyó inmediatamente en un taxón subespecífico con el nombre Graellsia isabelae galliaegloria, es decir, la "Gloria de Francia". Otro lepidóptero lleva como nombre genérico el de una población de la provincia de Sevilla, Tomares, por decisión de un entomólogo francés llamado Rambur, que encontró la especie Tomares ballus (por otra parte descrita años antes por Fabricius) en dicha localidad sevillana; hoy se conoce en gran parte de la península Ibérica, sur de Francia y norte de África; después se incluyeron más especies en este género, T. mauretanicus, del norte de África, T. nogelii, de Turquía, Armenia y del este de Europa, T. romanovi, de Armenia, T. callimachus, de Asia Menor, T. fedtschenkoi, del Turkestán y Pamir, etc, que lógicamente llevan el nombre válido del pueblo sevillano, con el que desde luego nada tienen que ver. Ejemplos de esta "preeminencia toponímica" hay a cientos y suelen ofrecer el topónimo del vecino más poderoso: muchas especies ibéricas se llevan el nombre hispanicus (v. gr. Copris hispanicus, un coleóptero) y están igualmente en Portugal; algo parecido ocurre con gallicus, germanicus, etc; lo contrario también ocurre (lusitanicus para especies españolas, etc), pero es mucho menos frecuente.

Otras veces el sesgo cultural procede de la ortografía aplicada a los nombres. Por la ya mencionada adopción del alfabeto latino, los nombres científicos de los animales han de estar escritos en estos caracteres, lo que excluye letras como la ñ, por lo que el fonema correspondiente se ha de representar de otro modo; así la vicuña se llama Vicugna vicugna (a la francesa), o las especies dedicadas al ilustre entomólogo Francisco Español, quedan con el extraño nombre de espanoli. El hecho de que el naturalista aragonés Félix de Azara (1746-1821) no utilizara el latín en sus denominaciones y descripciones de la fauna del Paraguay ha impedido que los nombres por él dados a numerosos vertebrados se hayan perpetuado, cuando fue él el primer des-

25 Véase AgEnjo, R. (1943) "Ensayo sobre la Graëllsia isabelae (Graells), el lepidóptero más bello de Europa (Lep. Syssph.)". Segunda parte. Eos, vol. 19, pp. 303-414 y VIEJO, J.L. (1992). "Graells y la Graellsia". Quercus, vol. 74, pp. 22-29. 


\section{JOSÉ LUIS VIEJO MONTESINOS}

criptor de una larga nómina de mamíferos, como el micuré (Didelphis albiventris) o el yaguarundi (Herpailurus yaguarondi).

Sin embargo, el etnocentrismo (que de otro modo podríamos llamar chovinismo) en la Biología no ha sido siempre tan inocente. En alguna ocasión, los naturalistas han asumido el impropio papel de propagandistas de las grandezas patrióticas con, y eso es lo más censurable, la pátina de imparcialidad que les proveía la Ciencia. Es el caso bien conocido del fraude de Piltdown. Hacia 1912, después de más de medio siglo de descubrimientos paleoantropológicos, ningún resto relevante había aparecido en las Islas Británicas; el 18 de diciembre de 1912, Charles Dawson y Arthur Smith Woodward presentaron en la Sociedad Geológica de Londres unos restos humanos hallados en una cantera de Piltdown; su aspecto era desconcertante, pues algunos fragmentos (la mandíbula inferior) eran claramente simiescos, mientras que el cráneo era muy semejante al de un humano actual. A pesar de la controversia desatada, los restos fueron en general aceptados como pertenecientes a un primitivo poblador de las Islas Británicas, al que se le denominó Eoanthropus dawsoni, "el hombre del amanecer de Dawson". Por fin el Imperio Británico podía aportar un súbdito al origen de la Humanidad. Con el tiempo, los restos de Piltdown fueron quedando como una rara anomalía en el registro fósil; hasta que en 1953 Oakley, Weiner y Le Gros Clark descubrieron el fraude: el cráneo y la mandíbula habían sido teñidos a propósito, los dientes limados y los restos fósiles de mamíferos acompañantes, traídos de algún otro lugar; la mandíbula era de orangután. Este caso, debidamente detallado por Weiner ${ }^{26}$, a la larga ha sido muy útil como punto de reflexión sobre los prejuicios de una sociedad que necesitaba encontrar una justificación científica a sus planteamientos sociopolíticos ${ }^{27}$.

\section{Epílogo.}

La historia de la biología nos enseña que, a pesar de los enormes avances del conocimiento científico, seguimos siendo herederos y deudores de la tradición antropocéntrica griega, lo que no es necesariamente perjudicial para el desarrollo científico, a menos que no lo asumamos y que permitamos que el prejuicio oculte o dirija nuestras investigaciones, descubrimientos o conclusiones.

Aún hoy nos debatimos entre las dos posiciones extremas de un inquietante péndulo: extraer al hombre del mundo zoológico, como único integrante de un reino separado, los Psicozoos, o incluirle en la misma familia que los grandes simios afri-

\footnotetext{
26 WEINER, J.S. (1955). The Piltdown forgery. London, Oxford University Press.

27 Para más detalles puede consultarse el ensayo de GouLd, S.J. (1983). El pulgar del panda. Madrid, H. Blume, $352 \mathrm{pp}$.
} 


\section{EL HOMBRE COMO ANIMAL: EL ANTROPOCENTRISMO EN LA ZOOLOGÍA}

canos. Los defensores de la primera posición conceden una capital importancia a las cualidades que identificamos con la humanidad: la conciencia, los valores morales y el lenguaje, que nos separan de nuestros parientes primates; piensan que el hombre, en algún momento de su evolución, ha cruzado un umbral y dejado atrás un abismo que nos separa de las bestias. Esta nueva categoría taxonómica, el Psicozoo, propuesta por Julian Huxley, no difiere demasiado de la visión evolutiva de Teilhard de Chardin. Por el contrario, los datos procedentes de la biología molecular nos acercan cada vez más a los simios africanos, con los que compartimos más del $98 \%$ del $\mathrm{ADN}$, coincidencia mayor de la que hay, por ejemplo, entre dos especies del género Equus, el caballo y la cebra; entre muchos biólogos hoy existe la opinión de que la separación evolutiva entre el hombre y el chimpancé sucedió hace unos 5 millones de años, mientras que el gorila se separó de la línea humana hace entre 8 y 10 millones de años. Pero, además de esta proximidad molecular, el linaje humano se acerca (si no se confunde) a los simios por los restos fósiles que han permitido reconstruir la cadena que nos une a los primates ${ }^{28}$.

La elección entre una posición y otra del péndulo es una cuestión metafísica, ya que la biología nos aleja del Psicozoo y nos acerca al simio. En cualquier caso, tanto si somos psicozoos, como si somos simios, no debemos ampararnos en nuestra singularidades y prejuicios, sean de especie, raza o cultura, para destruir, extinguir o someter a nuestros semejantes (animales, plantas u otros psicozoos), como expone Francesco Cavalli-Sforza en el prefacio al libro de su padre:

"Zo we zo: en una lengua de África central, el sango, significa 'un hombre es un hombre'. Una persona es una persona, todo ser humano tiene la misma dignidad. Es una verdad tan antigua como nosotros mismos, ofuscada en estos años de violencia racial, genocidios, guerras económicas y religiosas y venganzas seculares que devastan los países llamados civilizados"2y

\section{AGRADECIMIENTO.}

Debo expresar mi agradecimiento a los colegas que de algún modo han colaborado en este trabajo, en particular a Emilio Crespo, cuyos consejos, opiniones y correcciones han evitado que los aspectos de este trabajo que aluden a la cultura clásica greco-latina no hayan sido un completo desastre; y a Elena Escudero, Ángel Luque, Javier de Miguel y Adolfo Aguilar por sus saludables críticas. Y a Jorge, Pablo y Julia, porque a veces me han dejado escribir el artículo.

\footnotetext{
28 LEAKEY, R. y R. LEWIN (1994).

29 CAVAlli-SFORZA, L. y F. (1994). Quiénes somos. Historia de la diversidad humana. Barcelona, Crítica, 309 pp. cita en p. 9.
} 